\title{
A Novel Boost Conversion with High Voltage Ratio
}

\author{
Yu Chai, Xiaonan $\mathrm{Li}$ \\ College of Electrical and Control Engineering,Xi'an University of Science and Technology,Xi'an 710054 China
}

\begin{abstract}
When the traditional Boost converter duty cycle exceeds a certain value, the output voltage is not only increased, but will be reduced. Therefore, a new Boost converter with intermediate tap is proposed. By replacing the ordinary inductance of the traditional Boost converter with the inductance with the intermediate tap, the theoretical comparison is made with respect to the traditional boost converter. Under the same duty cycle, The Boost converter has a significant high gain ratio. Finally, the simulation and experimental analysis of the proposed new Boost converter are carried out by simulation software Pspice. The experimental results show that the new Boost converter has a significant high gain ratio compared with the traditional boost converter.
\end{abstract}

\section{Introduction}

In the development and utilization of new energy, solar energy and power generation, the need to pass the energy of solar modules to the grid, however, the solar panels generally produce lower voltage, generally below $60 \mathrm{~V}^{[1]}$, and for the output of $220 \mathrm{~V}$ AC grid voltage gridconnected inverter, the single-phase full-bridge topology required for the bus voltage of $380 \mathrm{~V}$ or even Higher ${ }^{[2-3]}$. There is therefore a need for a DC power converter with a high boost function to boost the voltage of the solar panel to match the voltage of the grid bus. If the traditional boost circuit to achieve this high voltage conversion, you need to work in a large duty cycle state, which will lead to the circuit switch and diode loss increases, affecting the conversion efficiency of the converter ${ }^{[4]}$. Based on this, a great deal of research has been done on the high-voltage converter at home and abroad, and a variety of converters are proposed for high boost.

The literature [5-8] proposed a built-in transformer unit circuit (Built-In Transformer Cell, BITC) high gain converter, but in order to eliminate the voltage spikes of the switch, the need to increase the absorption circuit, increasing the complexity of the circuit. The literature [9-11] proposed a cascade high gain converter, in the post-converter using coupling inductance technology, can effectively achieve the converter's high gain characteristics ${ }^{[12-13]}$, but the converter cascade will lead to low efficiency.

Based on this, a high gain converter based on a conventional boost converter is proposed. The conventional inductor of the conventional Boost converter is replaced with an inductor with an intermediate tap ${ }^{[13-14]}$, and the voltage gain is effective by selecting the appropriate turn ratio. To increases the voltage gain ratio. And this topology is simple and easy to implement ${ }^{[15]}$. Therefore, in the new energy power generation system has a good application value. The working principle and steady state characteristics of the proposed converter are analyzed theoretically. Finally, the circuit is built by the simulation software, and the correctness of the theoretical analysis is verified.

\section{New high boost converter}

\subsection{Traditional boost converter}

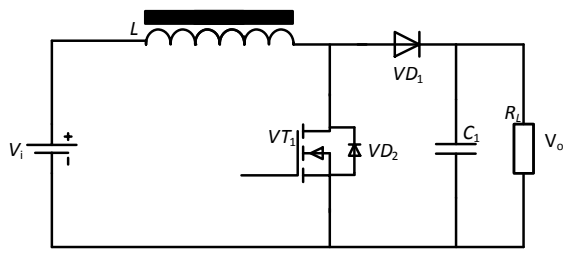

Figure 1. Traditional Boost converter circuit

The traditional Boost circuit shown in Figure 1, when VT1 conduction, the diode VD withstand back pressure and off, the equivalent circuit shown in Figure 2a, the current $i_{\mathrm{L}}$ flow through the inductor coil $L$, the current linear increase in energy to magnetic energy The form is stored in the inductance coil $L$. At this time, the capacitor $C$ discharge, only by the capacitor to the load $R_{\mathrm{L}}$ power supply, load current $I_{\mathrm{o}}$.

When VD is turned off, the equivalent circuit shown in Figure $2 \mathrm{~b}$, because the current $i_{\mathrm{L}}$ in the inductor $L$ can not be mutated, forced diode VD conduction flow, so that the inductor $L$ and power $V_{\mathrm{i}}$ at the same time to the

Corresponding author: larrynance@126.com 
capacitor $C$, load $R_{\mathrm{L}}$ power supply. When the inductor current is higher than $I_{0}$, the capacitor is charged and at the same time to provide power to the load; when the inductor current is less than $I_{\mathrm{o}}$, the inductor and capacitor discharge to the load $R_{\mathrm{L}}$ at the same time, to maintain $V_{\mathrm{o}}$ unchanged.
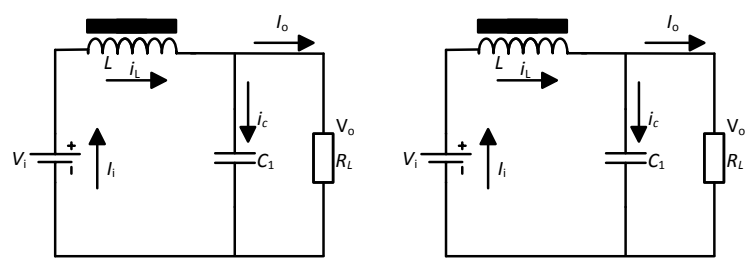

a) Switch VT1 turns on

b) Switch VT1 is off

Figure 2. Equivalent circuit for conventional boost converter operation

Define the duty cycle D as:

$$
D=\frac{T_{\text {on }}}{T_{\text {on }}+T_{\text {off }}}
$$

Where: $T_{\text {on }}$ is the time of VT1 conduction, and $T_{\text {off }}$ is the time of VT1 turn-off.

By analyzing the VT1 turn-on and turn-off of a period T, apply the volt-second balance to the inductor L:

$$
V_{i} D T=\left(V_{o}-V_{i}\right)(1-D) T
$$

From (2) the solution of the voltage gain ratio M:

$$
M=\frac{V_{o}}{V_{i}}=\frac{1}{1-D}
$$

Type (3) is the traditional Boost converter voltage gain ratio formula, we can see that when the duty cycle is 0.5 , the output voltage $V_{\mathrm{O}}$ is only 2 times the input voltage $V_{\mathrm{i}}$, and the duty cycle can not be too large, generally less than 0.8 .

\subsection{A boost circuit with a snubbed circuit for coupling inductors}

Application of coupling inductance with a buffer circuit boost circuit shown in Figure 3, inductance $L_{1}$ and inductance $L_{2}$ set the coupling coefficient of 1 can be considered an ideal transformer. Where $L_{1}$ turns are $N_{1}$, $L_{2}$ turns are $N_{2}$, and turns ratio $\mathrm{N}=N_{2} / N_{1}$. Capacitor $C_{1}$ and Diode $D_{1}$ clamp the capacitor and clamp diodes, respectively, and $D_{2}$ is the rectifier diode in the snubbed circuit.

The basic working principle is: When the switch $\mathrm{VT}_{1}$ conduction, the power supply to the $L_{1}$ charge, which inductor $L_{1}$ current linear growth, $L_{2}$ on the induced voltage through the clamping capacitors $C_{1}$ and $D_{2}$ and switch $\mathrm{VT}_{1}$ charge circuit to charge the capacitor $C_{2}$ charge, As shown in Figure 4a.

When the switch $\mathrm{VT}_{1}$ shut off, the output diode $D_{\mathrm{o}}$ conduction, $D_{2}$ is off. The supply voltage $V_{\mathrm{i}}$, the voltages on the inductor voltages $V_{\mathrm{L} 1}$ and $V_{\mathrm{L} 2}$, and the voltage on the capacitor $C_{2}$ form the charge loop to supply the load $R_{\mathrm{L}}$ to charge the capacitor $C_{\mathrm{o}}$, as shown in Figure $4 \mathrm{~b}$.

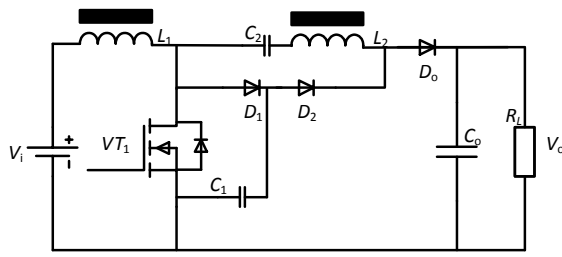

Figure 3. A boost circuit with a snubbed circuit for coupling inductors

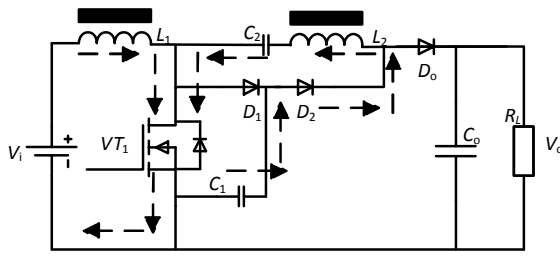

a) Switch VT1 turns on

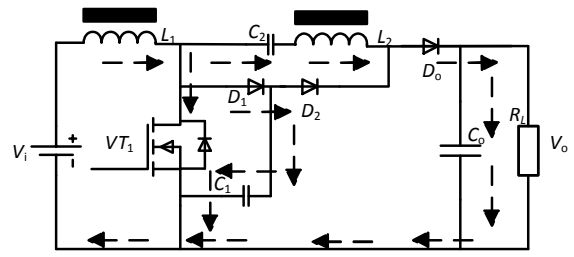

b) Switch VT1 is off

Figure 4. Working state diagram

By calculating the boost ratio $\mathrm{M}$ of the circuit is:

$$
M=\frac{V_{o}}{V_{i}}=\frac{2+N K}{1-D}+\frac{D(1-K)(N-1)}{1-D}
$$

In equation (4): $\mathrm{D}$ is the duty cycle, $\mathrm{K}$ is the coupling coefficient, and $\mathrm{N}$ is the turn ratio.

Therefore, when the coupling coefficient $\mathrm{K}$ is $1, \mathrm{M}$ is:

$$
M=\frac{V_{o}}{V_{i}}=\frac{2+N}{1-D}
$$


From the formula (5) can be obtained when the duty cycle is 0.5 , the output voltage for the input voltage of (4 $+2 \mathrm{~N})$ times, we can see that the circuit has a greater boost, but the circuit is relatively complex.

\subsection{New boost converter with intermediate tap inductor}

As shown in Figure 5, the boost converter with an inward tap inductor converts the inductance of a conventional boost converter with an inductor with an intermediate tap, and $L_{1}$ and $L_{2}$ are coiled on a core to form a coupling inductor with an intermediate tap. The $L_{1}$ as the primary, the number of turns $n_{1}, L_{1}$ as the secondary, the number of turns $n_{2}$, in a switching cycle, the circuit works as follows:

When the switch $\mathrm{VT}_{1}$ conduction, the diode $D$ by the back pressure off, the power $V_{\mathrm{i}}$ to $L_{1}$ charge, as shown in Figure 6a. When the switch is off, the diode turns on; the inductors $L_{1}$ and $L_{2}$ are connected to the supply $V_{\mathrm{i}}$ circuit to supply the load $R_{\mathrm{L}}$, as shown in Figure $6 \mathrm{~b}$.

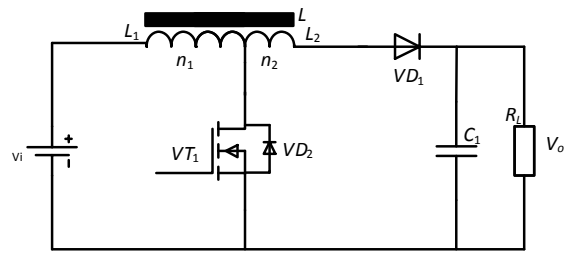

Figure 5. Boost converter circuit with intermediate tap inductor
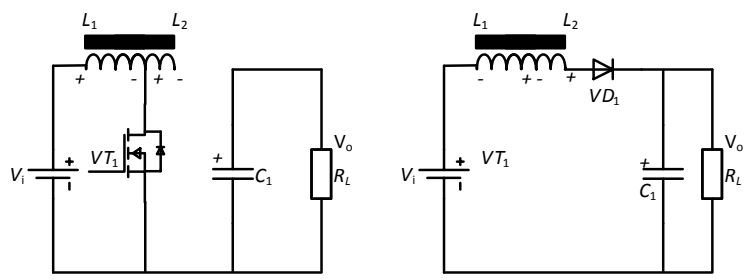

a) Switch VT1 turns on

b) Switch VT1 is off

Figure 6. Working state diagram

The boost ratio of the boost converter with intermediate tap inductance can be calculated by changing the flux of the magnetic flux in the tap inductor L for one cycle of turning on the switch VT1:

$$
M=\frac{V_{o}}{V_{i}}=\frac{1+N D}{1-D}
$$

From the formula (6) can be obtained when the duty cycle is 0.5 , the output voltage for the input voltage of (2 $+\mathrm{N})$ times, we can see that the circuit relative to the traditional boost converter has a greater boost ratio, the relative band coupling inductance has Buffer circuit of the boost converter, the circuit structure is simple, easy to control, so it has a wide range of applications.

\section{Simulation and verification}

In order to verify the correctness of the theoretical analysis, Pspice software is used to simulate the traditional boost converter, the boost circuit with the buffer circuit and the new boost converter circuit with the middle tap inductance. Figure 7, Figure 8, and Figure 9 shows the three circuits in the input voltage $100 \mathrm{~V}, \mathrm{~N}=$ $2, \mathrm{D}=0.5$, when the output voltage waveform. Through the simulation of the waveform, we can see that the traditional boost converter boost ratio is probably, the output DC voltage of $186 \mathrm{~V}$ or so, the theoretical value of $200 \mathrm{~V}$, so the circuit can improve the boost ratio, but the boost capacity is limited; Application coupling inductance with a buffer circuit output DC voltage of $690 \mathrm{~V}$ or so, the theoretical value of $800 \mathrm{~V}$, and the theoretical value of some gaps, which is related to the value of the capacitor inductance, but the circuit can significantly achieve the purpose of boost; The middle tap inductance of the new boost converter output voltage of $386 \mathrm{~V}$ or so, the theoretical value of $400 \mathrm{~V}$, and the theoretical value of the basic line.

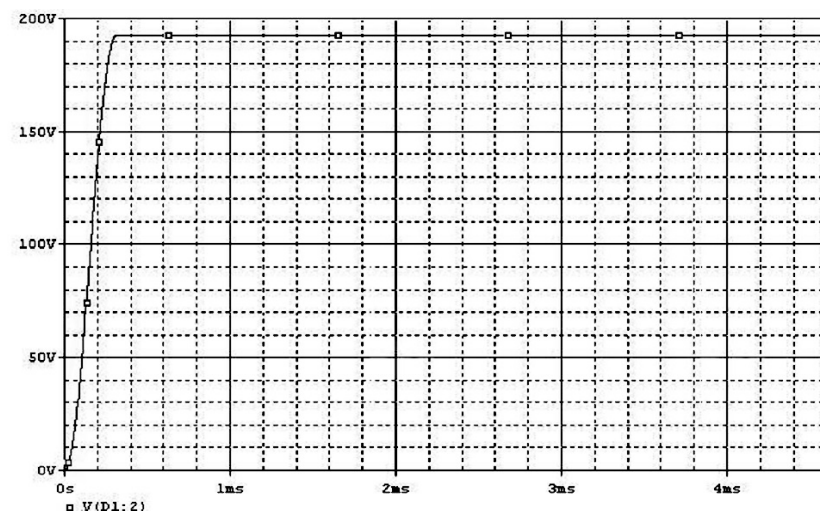

Figure 7. Traditional boost converter output voltage simulation waveform

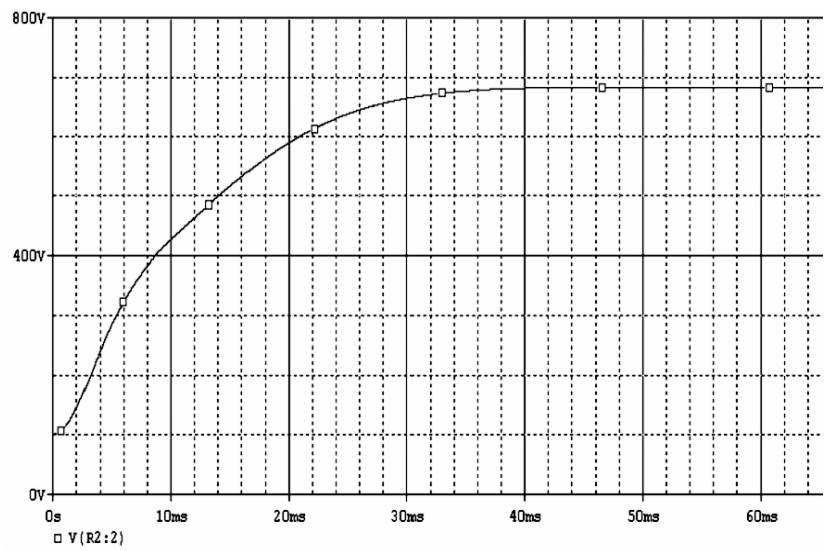

Figure 8. Application of coupling inductor with buffer circuit output voltage simulation waveform 


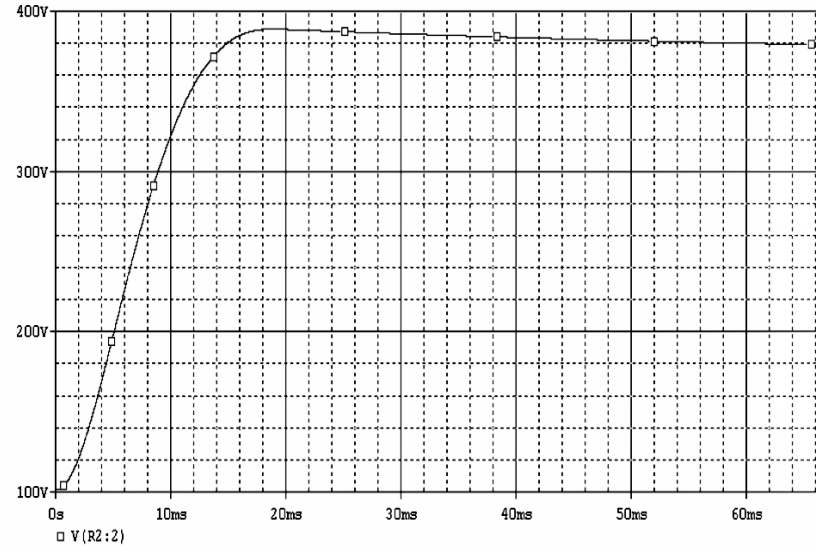

Figure 8. New boost converter output voltage simulation waveform with intermediate tap inductor

At the same time, the three circuit structures mentioned above and the devices used are compared, as shown in Table 1.

Table 1. Three kinds of boost circuit structure complexity comparison

\begin{tabular}{ccc}
\hline 拓扑类型 & 电路结构复杂度 & 升压比 \\
\hline 传统 Boost 变换器 & 简单 & $M=\frac{1}{1-D}$ \\
应用耦合电感的具有 & 复杂 & $M=\frac{1+N D}{1-D}$ \\
缓冲电路的变换器 & & $M=\frac{2+N}{1-D}$ \\
带中间抽头电感的 & 简单 & \\
Boost 变换器 & &
\end{tabular}

From the above table can be seen, through the cost of the circuit complexity, boost size than the size of the proposed new boost circuit, you can take into account the circuit cost and boost the advantages of relatively large, so this circuit has a larger research value.

\section{Conclusions}

Based on the theoretical analysis and simulation of the three booster circuits, it can be concluded that the proposed Boost converter with intermediate tap inductance has a higher boost ratio than other booster circuits, and the circuit structure is also relatively Simple and easy to control. So it has a high practical value in the application of distributed photovoltaic power generation system, uninterrupted power supply system and so on.

\section{References}

1. Yang B, Li W, Zhao Y, et al. Design and Analysis of a Grid-Connected Photovoltaic Power System[J].
IEEE Transactions on Power Electronics, 2010, 25(4):992-1000.

2. Zhao Q, Lee F C. High-efficiency, high step-up DCDC converters [J]. IEEE Transactions on Power Electronics, 2003, 18(1):65-73.

3. Yang L S, Liang $\mathrm{T}$ J, Chen J F. Transformerless DC-DC Converters With High Step-Up Voltage Gain[J]. IEEE Transactions on Industrial Electronics, 2009, 56(8):3144-3152.

4. Zhang Zhansong. Switching power supply principle and design [M]. Electronic Industry Press, 2004.

5. Li W, Wu J, Xie R, et al. A non-isolated interleaved ZVT boost converter with high step-up conversion derived from its isolated counterpart[C]// European Conference on Power Electronics and Applications. IEEE, 2008:1-8.

6. $\mathrm{Li} \mathrm{W}, \mathrm{Li} \mathrm{W}, \mathrm{He} \mathrm{X}$. Zero-voltage transition interleaved high step-up converter with built-in transformer[J]. Iet Power Electronics, 2011, 4(5):523-531.

7. Li W, Xiang X, Li C, et al. Interleaved High StepUp ZVT Converter With Built-In Transformer Voltage Doubler Cell for Distributed PV Generation System[J]. IEEE Transactions on Power Electronics, 2012, 28(1):300-313.

8. Chen Zhangyong, $\mathrm{Xu}$ Jianping, $\mathrm{Wu}$ Jianxue, et al.High-boost gain Boost converter of coupled inductance voltage doubling unit based on LC absorption circuit [J] .Journal of Electrical Engineering, 2016, 31 (2): 78-85.

9. Zhang Shiyu, XU Jianping, Yang Ping.Study on a Novel Single-switch High-gain Boost Converter [J]. New Technology of Electric Power, 2013, 32 (3): 000012-15.

10. Chen S M, Liang T J, Yang L S, et al. A Cascaded High Step-Up DC-DC Converter With Single Switch for Microsource Applications[J]. IEEE Transactions on Power Electronics, 2011, 26(4):1146-1153.

11. Hu X, Gong C. A High Voltage Gain DC-DC Converter Integrating Coupled-Inductor and DiodeCapacitor Techniques[J]. IEEE Transactions on Power Electronics, 2013, 29(2):789-800.

12. ZHOU Yu-fei, HAN Wen-xin. Coupled Inductance Single-stage Boost Inverter [J]. Proceeding of the CSEE, 2011, 31 (33): 61-67.

13. Cao Taiqiang, Liu Wei, Guo Xiaoying, et al. Dual Coupled Inductance Quadrature High Boost Gain DC-DC Converter [J] .Journal of Electrical Engineering, 2015, 30 (8): 104-112.

14. Hua Wei.Study on correction factor of chopper boost power factor with center tap inductor [J]. Electrical Drive Automation, 1999 (1): 32-35.

15. WANG Hao.Study on Topology of High Gain DCDC Converters for Building Integrated PV System [J]. Inverter World, 2012 (4): 56-61. 